\title{
A MINERAÇÃO EM MINAS GERAIS: PASSADO, PRESENTE E FUTURO
}

\author{
Olintho Pereira da Silva
}

\begin{abstract}
The first Portuguese pioneers who entered the newly discovered Brazilian lands were not succesful in the prospection of precious metals and stones. The primitive inhabitants were not enough cultivated to extract the metals from the rocks. They lived in the stone age yet. They became the sole valuable product of the "entradas" ventures. The mining in Brazil started when, in the end of the XVIII century, gold placers were found in the lands which were later named Minas Gerais.

The beginnings were terrible. The rich placers were depredated, the environment heavily spoiled by unskilled and thoughtless miners.

The Portuguese royal authorities tried to recuperate the mining activities by sending to Minas Gerais the German Metallurgical Technician, the baron W.L. von Eschwege who did a great effort to improve the gold and diamond mining works and to create alternative metallurgical undertakings.

During the Imperial Times, several English ventures were organized to continue exploiting gold deposits in Minas Gerais. The majority failled being succesfull. English capital left Brazil when the South African gold rush started in 1886 .

By 1910, American entrepreneurs tried to exploit the rich iron ore deposits found in the heart of Minas Gerais state. Political controversy prevented the American from implanting the projected iron ore undertakings. Now, looking far back, some doubts remain about the feasibility of the proposed ventures.

The year of 1934 marked important dates for the Brazilian mining legal structure. In 1942 were created the Companhia Vale do Rio Doce and the Companhia Siderúrgica Nacional.

In the second half of the 1960 decade started the best times for the Brazilian mining, but by 1982 the political and economical turmoils reverted the trend. Wild gold rush bursted out with great political support.

In 1988 a constitutional assembly elaborated a new Charter in which foreign capital was forbidden to control a mining company and the wild mining activities were deserved an encourageous treatment.

Minas Gerais has always been in the heart of old mining history. This prominent position was affected when the Carajás district came upon. Nobody may say this trend will be reverted.
\end{abstract}

\section{INTRODUÇÃO}

A descoberta do Brasil não despertou em Portugal, nas primeiras décadas que a seguiram, qualquer grande interesse exploratório. A pequena e grande nação ibérica estava mais interessada no desenvolvimento de seus canais comerciais que abasteciam a Europa com produtos orientais, as especiarias.

Foi, certamente, o sucesso das conquistas espanholas, no México e no Peru, que motivaram os interesses portugueses a explorar suas novas terras americanas, sem esquecer, também, as motivações religiosas advindas da Contra-Reforma, procurando compensar as perdas de espaço no Norte da Europa pela evangelização católica dos povos recémdescobertos.

O sucesso das empreitadas espanholas foi facilitado pelas conquistas de povos culturalmente avançados, já conhecedores dos metais por outro povo que, também, já possuía certa tradição de indústria mineral.

No Brasil foi diferente. As Entradas, organizadas por um povo sem tradição mineral, encontraram um povo que desconhecia o metal. Não havia tesouros a serem saqueados. O único produto das expedições exploratórias foi a escravidão do índio encontrado.

\section{UM MAU COMEÇO}

A situação se modificou quando foram encontrados os ricos aluviões auríferos de Minas Gerais, já no século XVII, onde o pouco conhecimento da arte da mineração era compensado pela riqueza do jazimento e facilidade de extração do metal, liberado e grosseiro. Além disso, escravos trazidos de regiões africanas frequentadas por árabes conheciam princípios de mineração aprendidos com esses povos. Esta foi certamente a primeira importação de tecnologia da mineração brasileira.

A atividade de mineração do chamado "Ciclo Econômico do Ouro" que se sobrepõe também à descoberta e extração de diamantes (século XVII) caracterizou-se por ações predatórias dos jazimentos, agressão violenta ao meio ambiente, imprevidente desequilíbrio que causava desabastecimento e, consequentemente, ciclos de fome que castigavam os pioneiros da mineração. As autoridades, como sempre, estavam ausentes nas funções de encaminhar soluções aos problemas, mas muito presentes na cobrança do quinto e na manutenção de seus privilégios corporativistas.

Ao esplendor mineral do século XVIII segue-se a decadência do século XIX e a migração dos mineradores 
mais previdentes para as fronteiras agrícolas, onde viveriam o novo Ciclo Econômico do Café.

\section{À PROCURA DE RUMO CORRETO}

A transferência da Corte Portuguesa para o Rio de Janeiro, em 1808, permitiu que D. João VI, então Príncipe Regente, tomasse conhecimento da inexorável decadência da mineração de ouro e de diamantes e procurasse recuperá-las. Foi, então, contratado pela coroa portuguesa o Barão Wilhelm Ludwig von Eschwege, formado na Universidade Göttingen, na Alemanha. O Barão von Eschwege chegou ao Brasil em 1810 com a missão de diagnosticar o estado da mineração brasileira e encaminhar-lhe soluções práticas e modernas para sua recuperação, assim como avaliar outros recursos minerais ainda não explorados, sugerindo formas de aproveitamento.

É impressionante observar os inúmeros obstáculos que o Barão teve de enfrentar para executar as tarefas para as quais foi contratado. Estes eram de toda ordem, e especialmente burocráticos. Pelo que se pode concluir, toda estrutura governamental procurava sabotar as iniciativas do Barão, embora deva-se também dizer que o Barão apresentava claras falhas de caráter, sendo muito vaidoso e prepotente.

Nos relatos dos naturalistas que visitaram o Brasil após 1808, atendendo convite da coroa portuguesa, somente uma observação positiva se fazia a respeito dos mineradores brasileiros. Eles eram mestres na arte de captar e conduzir água. Na verdade, é espantoso como eles conseguiam conduzir água nas encostas elevadas, de onde a lançavam para desmontar coberturas que lhes impediam o acesso ao corpo mineralizado, num processo fantástico de agressão ambiental.

A ação de Eschwege não se limitou a sugerir, projetar, aconselhar (e ser muito pouco acatado). Ele criou a primeira verdadeira empresa de mineração ao fundar a Sociedade Mineralógica de Passagem, com objetivo de dar continuidade à lavra da camada aurífera que mergulhava à margem direita do ribeirão do Carmo, em Passagem de Mariana. Na margem esquerda, a camada havia sido lavrada, após ter sido exposta pela remoção do minério de ferro a ela sobrejacente.

Em Passagem, o minério era, então, moído por pilões e o metal extraído por amalgamação.

O Barão von Eschwege foi incansável nos seus esforços de desenvolver a indústria mineral brasileira. Procurou visitar todas as ocorrências que lhe foram relatadas e fomentar o aproveitamento das que julgava úteis e econômicas. Em memorável esforço, tentou desenvolver o aproveitamento das galenas argentíferas dos sertões do Abaeté, cuja existência conhecera por amostras que chegaram à corte. Finalmente, dedicouse ao aproveitamento das reservas de minério de ferro, fazendo construir a Imperial Fábrica de Ferro, nas proximidades de Congonhas do Campo.

Eschwegwe fez uma estimativa do ouro produzido no Brasil no período que cobre o Ciclo Econômico do Ouro. Os números a que chegou não nos impressionam,pois correspondem a pouco mais que a produção anual da África do Sul, nos seus mais profícuos momentos. Entretanto, não nos é permitido comparar produções em termos de massa. O importante são os valores relativos das cousas. Uma tonelada de ouro no século XVIII possui um valor econômico muito diferente do valor de uma tonelada no século XX. O que importa é que a mineração foi a motivadora da colonização dos sertões do Brasil. Se com ela muitas mazelas vieram, não se pode esquecer que as virtudes e os pecados são a essência da condição humana.

\section{O SÉCULO XIX - AS COMPANHIAS INGLESAS}

As evoluções capitalistas efervescentes na Inglaterra foram campos férteis para criação de empreendimentos e aventuras especulativas. No início do séc.XIX floresceram em Londres organizações societárias que objetivavam desenvolver empreendimentos auríferos no Brasil, levantando os necessários recursos pela venda de participações no já consolidade mercado de capitais. Como sempre, nessas ocasiões, muitas das organizações revelaram-se simples falcatruas destinadas a tomar dinheiro de incautos investidores. Outras, tendo levantado recursos, enviaram procuradores bizarros e despreparados, por vezes desonestos, que adquiriram aluviões exauridos, sem continuidade de mineralização primária, evidenciando seu despreparo ou sua desonestidade, ou ambas.

Algumas se revelaram empreendimentos sérios que aqui se consolidaram, sendo que a Mineração Morro Velho S/A é a única evolução que ainda permanece, tendo já completado 160 anos de atividades mineiras. É interessante, mas lastimável, notar que a presença das empresas inglesas de mineração de ouro no Brasil, com todo o drama humano que isto representou, não despertou um real e válido interesse entre nossos historiadores e sociólogos, tão numerosos, se recenciados por títulos e atos de autopromoção. É louvável a recente iniciativa da Mineração Morro Velho S/A, que organizou seu Memorial, sinalizando que pretende proteger, resgatar, conservar a sua memória, impedindo que com ela aconteça o que destruiu outros valiosos acervos. Nós ousamos sugerir à Mineração Morro Velho S/A lançar um desafio a quem queira e possa, poder no sentido de ser capaz, de redesenhar o drama da presença dos ingleses em Minas Gerais, bem como dos que por eles foram aqui trazidos, italianos e espanhóis etc.

As empresas inglesas que aqui se consolidaram foram introdutoras de novas e revolucionárias tecnologias, especialmente processos hidrometalúrgicos para extração do ouro de minérios com baixo grau de liberação para o metal. Pelas mãos dos ingleses, as minas de ouro brasileiras conheceram tempestivamente os processos de extração do metal por 
cloração e, posteriormente, por cianuretação, aqui implantados no século XIX.

Nas lavras subterrâneas, além de métodos modernos, os ingleses foram mestres em implantar inteligentíssimos sistemas condicionantes das frentes, pois econômicos e eficientes.

O que lamentamos, embora não saibamos exatamente explicar, é que a presença de técnicos brasileiros era rara nestas unidades industriais. A mão de obra privilegiava os ingleses, italianos, espanhóis e escravos.

A despeito da visão bastante correta do Segundo Império ao tratar dos assuntos da indústria mineral, os esforços fomentadores não resultaram em avanço notável no setor. O século XIX recebeu, então, a mineração brasileira no mais lastimável estado de decadência. Assistiu aos esforços envidados para recuperá-la e à chegada de recursos estrangeiros que modernizaram-na. Ele assistiu também à inexorável decadência da incipiente siderurgia que se desenvolvera em São Paulo e Minas Gerais, e que não acompanhou a evolução tecnológica do processual siderúrgico.

A Primeira República, com seu caráter basicamente positivista, assumiu uma posição reativa à política do Império, não reservando à mineração nenhum espaço privilegiado, tratando-a como parte do conjunto de atividades industriais, indistintamente, desconsiderando os riscos inerentes do setor.

Porém, foi exatamente neste período histórico que o mundo econômico tomou conhecimento das grandes reservas de minério de ferro existentes no coração do estado de Minas Gerais. Como é difícil compreender que essas reservas, anunciadas por todos os grandes naturalistas que visitaram o Brasil, tenham sido por tanto tempo esquecidas, e que os mineradores ingleses, que por tanto tempo aqui estiveram, não tenham transmitido o conhecimento do gigantismo e da qualidade das reservas, nem que seja por curiosidade intelectual, se é que foram capazes de avaliar a pobre logística que lhes impedia o aproveitamento. Organizaram-se, então, nos Estados Unidos, as empresas que objetivavam aproveitar as reservas anunciadas em Estocolmo.

Grandes programas exploratórios foram implantados pelos americanos, utilizando técnicas nunca vistas pela mineração brasileira. Infelizmente, estes trabalhos de pesquisa foram executados sem qualquer participação de brasileiros que não tiveram oportunidade de tirar proveito tecnológico do esforço empreendido.

Acostumamo-nos a ouvir, e muito aplaudir, o posicionamento das autoridades mineiras e brasileiras que inviabilizaram os empreendimentos norteamericanos que objetivavam aproveitar o minério de ferro do Quadrilátero Ferrífero na décade de 1910. Em verdade, o posicionamento xenófobo atrasou de 30 anos o início da verdadeira mineração de ferro em Minas Gerais, somente recomeçada timidamente na década de 1940.
Gostaríamos que o assunto voltasse desapaixonadamente ao exame crítico da atual geração de técnicos. É, porém, discutível que os investidores alcançassem sucesso, se o ambiente político lhes fora acolhedor. Em verdade, numa visão já em tempos afastados, pode-se colocar em dúvida a viabilidade dos empreendimentos, pois é duvidoso que o transporte marítimo da época garantisse a competitividade do minério nos centros consumidores de então. Mesmo para as hematitas compactas, então largamente usadas nas aciarias americanas, talvez os empreendimentos ainda fossem prematuros. O que não podemos concordar é que aqueles que inviabilizaram por razões políticas os empreendimentos, possam ser hoje louvados como heróis da nacionalidade. Se a posição de intransigência se justificava na possibilidade de impor vantagens para o Brasil, a estimativa de poder de barganha foi exagerada. Não se justificam barganhas, quando deve haver unicamente regras racionais pré-estabelecidas.

\section{A MINERAÇÃO E A NOVA REPÚBLICA DE 1930}

A Nova República, a primeira nova de 1930, pois a segunda nova viria em 1986, um novo conceito no arcabouço legal da mineração foi consagrado, pela definição do bem mineral como propriedade da Nação, cujo aproveitamento seria concedido a pessoas de direito privado.

O ano de 1934 representa um marco na história da mineração brasileira, pois foi nele que se criou o Departamento Nacional de Produção Mineral - DNPM (Decreto número 23.979, de 08/03/1934), assinou-se (em 10 de julho de 1934) o Código de Minas e promulgou-se a Carta Constitucional de 1934, de curta duração mas de grande repercussão no destino da mineração brasileira.

\section{ORIGEM E EVOLUÇÃO DO DNPM}

Voltemos ao período do Reino Unido na busca das origens do DNPM, pois até então a mineração somente era lembrada pela Coroa Portuguesa para receber seu quinto.

O primeiro órgão público a ter legalmente de tratar da geologia foi o Museu Nacional, criado em 03/02/ 1818. Sua estrutura sofreu completa reorganização em 03/02/1842, passando a existir uma seção para tratar dos assuntos, dentre outros, de "Mineralogia, Geologia e Ciências Exatas".

Em 25/02/1843 foi criado, na Secretaria do Estado dos Negócios do Império uma seção “... de Agricultura, Mineração ...", verdadeira semente do atual DNPM.

Em 28/07/1860, pelo Decreto núm. 1067 foi criada a Secretaria dos Negócios da Agricultura, Comércio e Obras Públicas, a que foi atribuída competência pelo Decreto $n^{\circ} 2747$ de 16/02/1861, para inspecionar “...a mineração, excetuada a dos terrenos diamantinos, cuja 
administração e inspeção continuam a cargo do Ministério da Fazenda".

Pelo Decreto n 6026 de 06/11/1875 o Imperador D. Pedro II criava a Escola de Minas de Ouro Preto que se organizou em 12/10/1876, numa tentativa concreta de introduzir a modernidade tecnológica na mineração brasileira.

Com o advento da República, a mineração não mereceu nenhum tratamento especial e ela foi ligada ao Ministério da Indústria, Viação e Obras Públicas, criado pela Lei $\mathrm{n}^{\circ} 23$, de outubro de 1891.

Mais tarde, em 29/12/1906, pelo Decreto Legislativo n 1906 criou-se uma Secretaria de Estado que recebeu a denominação de Ministério dos Negócios de Agricultura, Indústria e Comércio, quando se observa uma maior preocupação com a mineração, pois dentre seus encargos destacam-se o estudo e despacho de “... mineração e legislação, exploração e serviço geológico, estabelecimentos metalúrgicos e escolares de minas".

Esta preocupação torna-se mais nítida com a criação, am 10/01/1907 (Decreto nº 6323), do Serviço Geológico e Mineralógico do Brasil, vinculado ao Ministério de Estado da Indústria, Viação e Obras Públicas.

Posteriormente, o Serviço Geológico e Mineralógico voltou ao âmbito do Ministério da Agricultura ali permanecendo, já na forma de DNPM, até a criação do Ministério de Minas e Energia, criado pela Lei n 3782 de 22/07/1960. Em 08 de março de 1934 foi, então, criado o Departamento Nacional de Produção Mineral, pouco antes da assinatura do Código de Minas de 1934.

\section{A SEGUNDA GUERRA MUNDIAL E A MINERAÇÃO}

O advento da Segunda Grande Guerra Mundial provocou a necessidade de dirigir-se à mineração especial atenção. O transporte brasileiro baseava-se, sobretudo, na rede de ferrovias e na navegação, ambas basicamente movidas a vapor, queimando carvão mineral e lenha.

Com a guerra, tornou-se difícil o abastecimento do País com combustível importado, obrigando a que se desse especial atenção à mineração de carvão e, em menor escala, à de turfas.

O petróleo, todo importado, foi substituído, parcialmente, por álcool hidratado ou gás de madeira.

$\mathrm{O}$ abastecimento de metais ficou praticamente reduzido à reciclagem, e aos recursos da incipiente siderurgia a carvão de madeira, e a modestas fundições.

As importações tornaram-se difíceis, não só pela escassez, como também pelos ataques que os navios mercantes sofriam nos oceanos.

Por outro lado, os países beligerantes careciam de matérias primas, abrindo oportunidades para certos produtos minerais brasileiros, como Manganês, Quartzo, Scheelitas, Monazitas.
A impossibilidade de adquirir enxofre nativo obrigou a que se procurasse a alternativa de aproveitamento das piritas, como já acontecera na primeira guerra.

Entretanto, o fato mais importante ocorrido nessa época foi o acordo de Washington, pelo qual, além de outras atitudes que não dizem respeito à mineração, $\mathrm{o}$ Brasil reforçaria o abastecimento das aciarias aliadas com suas hematitas compactas de alto teor metálico e, para tanto, receberia apoio financeiro para construir um terminal marítimo, modernizar uma ferrovia e abrir uma mina na bacia do Rio Doce. Além disto, receberia também apoio financeiro para construir uma moderna indústria siderúrgica integrada, totalmente verticalizada, das minas aos produtos acabados, em 1942.

Assim nasciam, em 1942, a Companhia Siderúrgica Nacional e a Companhia do Vale do Rio Doce, marcoa importantes da indústria mineral brasileira.

Nos primeiros anos que se seguiram ao acordo de Washington, as atividades de mineração da CSN, secundárias em relação ao seu objetivo maior, foram maiores que as da própria CVRD, pois envolviam operação de lavra e tratamento de minério de ferro em escala tão grande como a da CVRD, de carvão, calcário, dolomita e manganês. A CVRD somente atingiu dimensões notáveis na década de 1960. Para se ter uma idéia das dimensões, em 1952, dez anos após sua fundação, a CVRD exportou 1.541.285 t de minério de ferro; em 1957, 2.966.261 t e, em 1962, já numa fase realmente representativa no contexto dos fornecedores de minério de ferro, exportou 6.138.902 t.

\section{A MINERAÇÃO E A GUERRA FRIA}

No ano de 1950, a chamada guerra fria que se iniciara logo após o término da segunda grande guerra mundial, já dividia o mundo e colocava o Brasil no campo das disputas. Este ano marca, também, a volta do antigo ditador, Getúlio Dorneles Vargas, à presidência da república, agora eleito em pleito de incontestável representabilidade.

Após a eleição, o presidente Getúlio Vargas abraçou a causa nacional-populista, mas a adesão das correntes esquerdistas às suas idéias só se deram depois de sua morte, em 24 de agosto de 1954. Quem duvidar do que aqui se afirma deverá ler os jornais do PCB nos dias anteriores ao dia do suicídio do velho presidente.

Este posicionamento político-social teve grande influência na evolução da mineração brasileira. Dele vem a idéia triunfante de monopólio estatal do Petróleo e dos Minerais Radioativos. O acerto ou erro deste posicionamento vem sendo constantemente discutido.

Há outros fatos que terminaram esquecidos e são esses que gostaríamos de reexaminar, pois seus resultados podem ser apreciados.

A chamada mineração de areias pesadas iniciou-se no Brasil ainda no século XIX, objetivando a extração de areias monazíticas. Das areias monazíticas chegouse ao rutilo e ao zircão. Da simples exportação de areias 
monazíticas passou-se à indústria dos cloretos de terras raras e certamente chegaria aos óxidos, em curto prazo, dado seu dinamismo.

Acontece que as areias monazíticas são radioativas e este tem sido o drama da indústria das terras raras. Os rejeitos de tório são perigosos e de aproveitamento muito restrito.

No Brasil de 1950, a contaminação das areias monazíticas foi motivo de campanha nacionalista. Os exportadores foram acusados de contrabandistas de combustível nuclear. A campanha contra o aproveitamento das areias pesadas foi tão ampla que foi necessário estatizar o setor, acalmando a virulência enlameadora dos empresários que ousavam continuar a aproveitar os depósitos costeiros de minerais pesados.

Uma vez estatizado, o setor estagnou-se e se degradou até a extinção pelo recente fechamento da usina de Santo Amaro. Fim melancólico de uma aventura estatizante e nacionalista.

A mineração de minerais pesados na Austrália é posterior à brasileira, nasceu exatamente quando estatizávamos a nossa, e hoje é uma potência invejável, ocupando um espaço que o Brasil poderia ter ocupado.

Na década de 1950, a empresa norte-americana The Hanna Mining Company (1994) adquiriu o controle da St. John d'el Rey Mining Company, dividiu as propriedades, incorporando-as a duas empresas Mineração Morro Velho S/A e Mineração Novalimense $\mathrm{S} / \mathrm{A}$, esta última recebendo as jazidas de minério de ferro, parte do acervo da St. John d'el Rey. Iniciou-se feroz campanha nacionalista para impedir que a Hanna implantasse um projeto que contemplava a construção de uma nova ferrovia de Minas ao litoral (hipótese mais provável) e de um terminal oceânico para carregamento de navios com minério de ferro. A única forma de conseguir vencer as resistências foi a organização de um "joint-venture" que, comandada pelo empresário Sr. Augusto de Azevedo Antunes, com a denominação de Minerações Brasileiras Reunidas S/A - MBR, num plano bem menos audacioso, abriu um novo sistema logístico de exportação de minério de ferro. Hoje, o Hanna não faz parte do quadro de acionistas da MBR, desmentindo as calúnias lançadas sobre o empresário brasileiro, acusado de simples "testa de ferro" dos interesses dos "trusts" americanos. "Trust"era o palavrão utilizado pelo coro nacional-populistacomunista, na época.

Também foi na década de 1950 que se iniciou a orquestração que visava impedir a implantação da "joint-venture" organizada pelo Sr. Augusto Azevedo Antunes com o "trust" siderúrgico Bethlohem Steel Co., de que resultou a ICOMI. O consórcio havia vencido uma licitação que objetivava aproveitar as reservas de manganês da Serra do Navio, então território do Amapá.

Nessa época, para cada tonelada de aço produzida, a siderurgia consumia mais que $50 \mathrm{~kg}$ de manganês. $\mathrm{O}$ grande produtor de aço eram os Estados Unidos da América, país carente de reservas de minério de manganês. Assim, o verdadeiro objetivo da campanha era prejudicar a siderurgia norte-americana, proibindo a exportação do minério do Morro da Mina (LafaieteMG), e impedindo a abertura da Serra do Navio.

Justificava-se a campanha na necessidade de proteger a siderurgia brasileira no futuro. O lema era "minério não dá duas safras".

Felizmente, os defensores da inércia mineral não conseguiram vencer a força de resistência de alguns empresários e formadores de opinião. A ICOMI foi implantada, o Morro da Mina explotado, tudo isso na melhor hora, com ótimos preços no mercado internacional.

Hoje, a evolução do processo siderúrgico reduziu o consumo de manganês a $5 \mathrm{~kg}$ por tonelada de aço produzida e o minério de manganês passou a ter valor pouco significativo.

Outro fato a ser relembrado, típico da década de 1950, foi o que aconteceu com o Nióbio. No princípio, o aproveitamento do nióbio de Araxá restringia-se à concentração do pirocloro. Acontece que o concentrado de pirocloro é ligeiramente radioativo.

Logo, a empresa explotadora foi acusada de estar exportando, clandestinamente, urânio. Na verdade, seu concentrado de pirocloro era multado pela presença nociva de elementos radioativos.

Para vencer a ignorância, a empresa teve de aceitar uma imposição: repor à Comissão Nacional de Energia Nuclear, em forma de combustível nuclear, o urânio que exportava em seu concentrado. O exportador era, então, punido duas vezes. Pelo governo brasileiro e pelo comprador, indevida e devidamente.

A verticalização de empreendimentos pôs fim à aberração. Ao reduzir-se o pirocloro em ferro-liga de nióbio, a contaminação radioativa é escorificada. A CNEN perdeu sua mais confiável fonte de urânio, a qual nunca mereceu.

O pensamento nacional-populista-comunista continuou a manter sua influência no destino da mineração brasileira e teve seu momento de glória na Assembléia Nacional Constituinte, que promulgou a Constituição de 1988, vencendo o pensamento liberal em todo termo que se refere à mineração, obtendo uma consagradora vitória que alguns dizem ser de pirro $1 / 4$

\section{DUAS DÉCADAS DE AVANÇOS}

A mineração entrou na década de 1960 com o que supunha ser uma grande vitória. Foi criado o sonhado Ministério das Minas e Energia, em 1961.

Após o curto governo Jânio Quadros, já no tumultuado governo João Goulart, a mineração viu ser nomeado Ministro das Minas e Energia o Dr. Eliezer Baptista da Silva, o que garantiu a continuidade na implantação dos planos de expansão da CVRD, colocando-a entre uma das mais confiáveis alternativas para fornecimento de minério de ferro ao mercado mundial.

Antes da inauguração do Terminal Oceânico de Tubarão, o governo João Goulart já fora deposto e o 
governo militar autocrático chefiado pelo Marechal Castelo Branco deu continuidade à implantação do plano de expansão da CVRD.

Aos primeiros governos militares a mineração deve seu período de maior crescimento e esplendor. Já em 1967, reorganizado o estado, foi publicado o Código de Mineração, modernizador dos princípios do antigo Código de Minas. O Código de Mineração de 1967 retirou do proprietário do solo a preferência que lhe era anteriormente reservada na concessão de Direitos Minerários, garantindo-lhe, porém, justa indenização por danos e perdas, bem como participação nos resultados da lavra.

Prestigiada a mineração, foi possível impedir a depredação das jazidas de cassiterita recém-descobertas em Rondônia, ameaçadas que estavam por hordas de marginais anto-intitulados "garimpeiros".

A abertura que se deu com o novo Código de Mineração, a modernização das estruturas burocráticas do estado, a estabilidade econômica do País atrairam toda sorte de capitais para mineração: do exterior, vieram todas as grandes empresas tradicionais de mineração juntarem-se às que aqui já se encontravam; o empresário brasileiro também passou a considerar a mineração uma alternativa para investimento e o estado, tanto pela administração federal como por algumas administrações estaduais, destinava vultosos recursos para mineração, não só em programas de exploração geológica básica, mas também como empreendedor de mineração.

Os resultados fizeram-se sentir imediatamente, especialmente pelo desenvolvimento do que passa a ser Grupo CVRD e Grupo CAEMI. O minério de ferro assume o papel de alavanca do desenvolvimento mineral do País, e assim permanece até hoje.

O grande surto de desenvolvimento da mineração no País deu-se, sobretudo, pela passagem do Sr. Antônio Dias Leite pelo MME que, como Dr. Baptista, provinha da CVRD, e soube, como este, honrar a expectativa dos mineradores.

Entretanto, algumas medidas tomadas na época foram bastante contestadas, especialmente a criação da Companhia de Pesquisa de Recursos Minerais. Algumas correntes de pensamento no meio mineral julgavam que ação exploratória (pesquisa, no termo do $\mathrm{CM}$ ) do estado deveria restringir-se às empresas estatais já organizadas. Outro órgão, além do DNPM, poderia se encarregar de explorações geológicas básicas, sem direito a requerer áreas. Este pensamento, vencido na época, parece que tende a triunfar no presente. Este é, certamente, um tema honesto e válido a ser rediscutido, com base nos resultados conseguidos nos melhores momentos do passado, excluindo-se períodos de crise.

\section{AUTORITARISMO, EQUÍVOCO E PERMISSIVIDADE}

O Código de Mineração de 1967 atende rezoavelmente aos anseios dos mineradores, e críticas que lhe são feitas não superam suas virtudes, podendo- se creditar-lhe um saldo favorável. Entretanto, alguns reparos devem ser feitos à política que norteou sua aplicação, da qual se espera ter, um dia, os rumos corrigidos:

\section{Permissividade na emissão de Alvarás de Pesquisa}

O espírito do C.M. não permite a obtenção de um número indefinido de Alvarás de Pesquisa. Os anseios dos grandes empreendedores seriam atendidos pela figura do Reconhecimento Geológico.

Fugindo das limitações deste direito, os mineradores optaram pela criação de subsidiárias cuja única finalidade era a obtenção de indefinido número de Alvarás de Pesquisa, e o DNPM aceitou. Ora, não se pode impedir que alguém crie indefinido número de empresas de mineração, mas pode-se ser rigoroso, como sempre deveria ter sido, no acolhimento de Pedidos de Pesquisa. Afinal, empresa de capital insignificante não pode ter capacidade financeira para implantar planos de pesquisa que ultrapassem seus recursos que, na realidade, são inexistentes. Se o acionista é poderoso, imponha-lhe a integralização do capital segundo o cronograma financeiro do plano de pesquisa, com obrigação de comprovação.

O DNPM possui, dentro do CM, mil ferramentas para impedir a proliferação de Pedidos de Pesquisa, todas elas agindo diretamente no bolso de quem está abusando.

\section{Permissividade na comercialização de títulos minerários}

O princípio de que o direito minerário somente pode ser comercializado após ter seu relatório de pesquisa aprovado sempre foi consagrado na legislação minerária. Assim, um Alvará de Pesquisa não é um direito negociável, até que tenha seu relatório de pesquisa aprovado, quando o corpo pesquisado possa ser considerado um bem minerário (C.M. Art.31).

Em 29/01/71, por Instrução do Ministro das Minas e Energia (núm. 2029,DOU de 08/02/71), alterou-se esse princípio, permitindo que se incorporasse à empresa em organização ou já existente qualquer alvará de pesquisa. Esta instrução é claramente ilegal e foi elaborada por razões casuísticas. Por seu intermédio abriu-se o caminho para a indústria dos alvarás de pesquisa, ferindo profundamente o espírito do C.M.

\section{Permissividade na renovação de alvarás de pesquisa}

É compreensível que, ao preparar um plano de pesquisa, o minerador possa subestimar o volume do trabalho a ser implantado. Daí a necessidade de revisão do plano de pesquisa que, em certos casos, poderá exigir a prorrogação do cronograma de implantação e, consequentemente, ultrapassar os limites do prazo estabelecido pela lei.

A prorrogação deveria ser, então, criteriosa e somente concedida ao minerador que houvesse executado o plano de pesquisa proposto ou a este superado, que se mostrou ainda insuficientemente. 
Todos os profissionais sabemos que a maior parte dos pedidos de prorrogação da pesquisa não se justifica na realidade da insignificância dos trabalhos já executados e são simples artifícios de permanência do Direito.

\section{Permissividade na suspensão de lavra}

É notório que grande parte das lavras paralizadas justificam-se na incapacidade técnico-econômica do detentor da concessão ou no interesse de manter reserva para um futuro irracional, pois que ultrapassa menos razoável futurologia. Isto é um desrespeito ao princípio constitucional de propriedade do bem mineral. Mas, de empresários que falam na "mina (querendo dizer jazida) de minha propriedade", não se pode esperar atitudes diferentes.

Uma ação mais enérgica do DNPM, estritamente na letra e no espírito do Código de Mineração, sem qualquer arrogância autoritária, teria impedido e poderá impedir as distorções e aberrações que muito entravam o desenvolvimento da mineração brasileira, e nos teria poupado de assistir a espetáculo circense ocorrido em plena Assembléia Nacional Constituinte, quando parlamentares incautos e incultos desfilaram carnavalescamente com o mapa de controle de áreas e com um livreto da lavra do CNPQ, gentilmente patrocinado pelo contribuinte.

\section{O RETROCESSO}

A despeito dos muitos e perturbadores equívocos ocorridos na década de 1970, ela corresponde ao período áureo da mineração brasileira. Nunca se investiu tanto em trabalhos exploratórios, pesquisas tecnológicas, formação pessoal. Grandes projetos foram implantados, tendo o País ocupado uma posição importante no cenário das atividades de mineração, atraindo recursos de toda origem para o setor.

Os gráficos das Fig. 1 a 6 ilustram a evolução do investimento na exploração mineral e na indústria de mineração (lavra) no Brasil entre os anos de 1978 e 1992 (Fonte: DNPM).

A década de 1980 engloba o período de decadência. Agrava-se a crise econômica mundial, enfraquecendo os investidores internacionais tradicionais. $\mathrm{O}$ estado brasileiro é brutalmente atingido pela crise econômica e paga caro por sua imprevidência. O regime militar enfraquece, e cede a todo tipo de pressão demagógica, admitindo, inclusive, como solução do problema social, o violento florescimento da marginalidade empresarial que se auto-denominou "garimpo". O Ministério das Minas e Energia foi sucessivamente ocupado por cidadãos bizarros. Cada novo ministro conseguiu superar o anterior em bizarria. O próprio meio profissional aderiu, em grande parte, às idéias mais esdrúxulas.

Todo este ambiente de decadência e pessimismo criou a cultura que prevaleceu para a mineração na elaboração da Carta Constitucional de 1988. O texto da Carta Constitucional reserva à mineração o tratamento discriminatório ao declará-la agressora do meio ambiente, como se também não o fora toda outra atividade viva sobre o planeta. À marginalidade mineral, a nova carta dedica longo e incentivoso, reverencioso palavreado, da mais pura lavra demagógica. A vingança do verdadeiro minerador é que Marginal se define por opção, ficando à margem da Lei. Colocá-lo em destaque na Lei Magna, mesmo que seja para prestigiá-lo, é pura estultice. Ele não aceitará tão honrosa homenagem.

Entretanto, é bom que se esclareça que a violenta queda de disponibilidade de recursos para mineração, especialmente para exploração geológica, é anterior à "Nova República (1986)". A nova Carta Constitucional veio somente agravar a tendência, tornando-a inexorável. Basta examinar as estatísticas publicadas pelo DNPM para que se comprove a afirmativa.

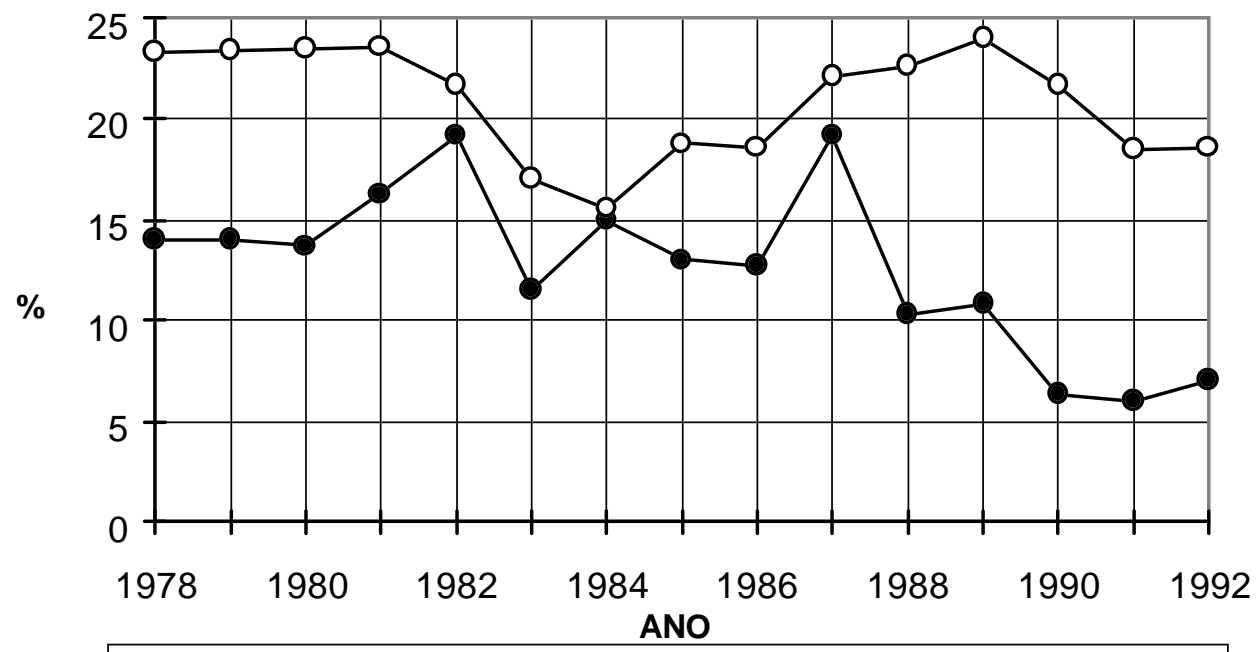

—— INV.TOTAL MINERAÇÃO/VPM (\%) —— INVEST.INTERNO BRUTO (\% PIB)

Figura 1: Comparação entre investimentos totais na economia vs. investimentos na mineração, no Brasil, 1978-1992.

Figure 1: Comparison between total industrial investment vs. investment in the mining industry. 


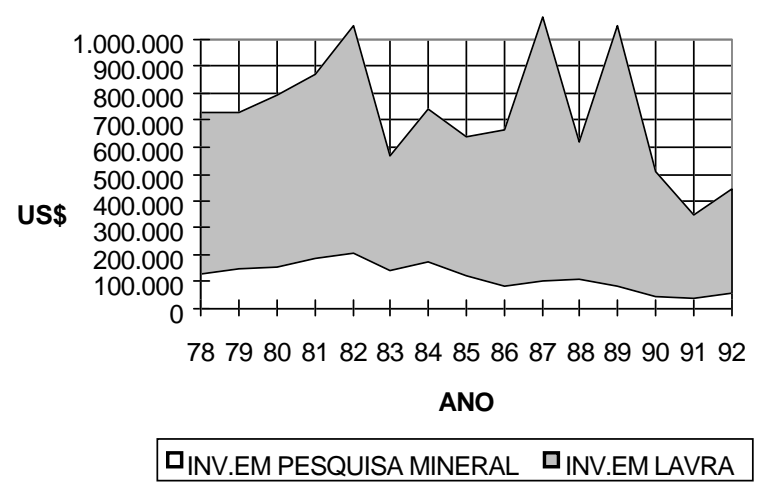

Figura 2: Investimentos em mineração, 1978-1992. Figure 2: Investment in the mining industry in Brazil, 1978-1992 (white: mineral exploration, shaded: mining).

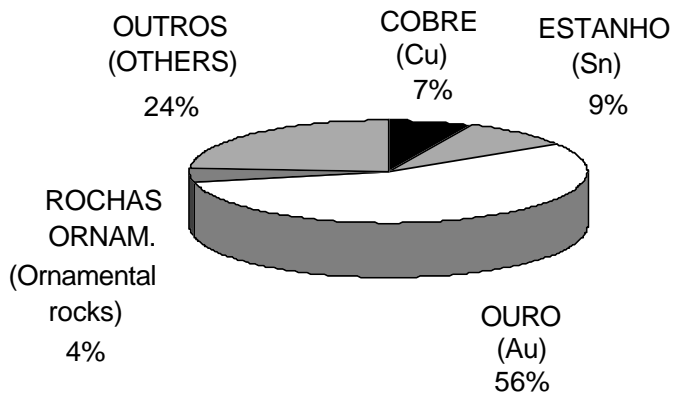

Figura 3: Investimento em pesquisa mineral (19781992). Participação relativa das principais substâncias.

Figure 3: Investment in mineral exploration in Brazil, 1978-1992, broken down to principal commodities.

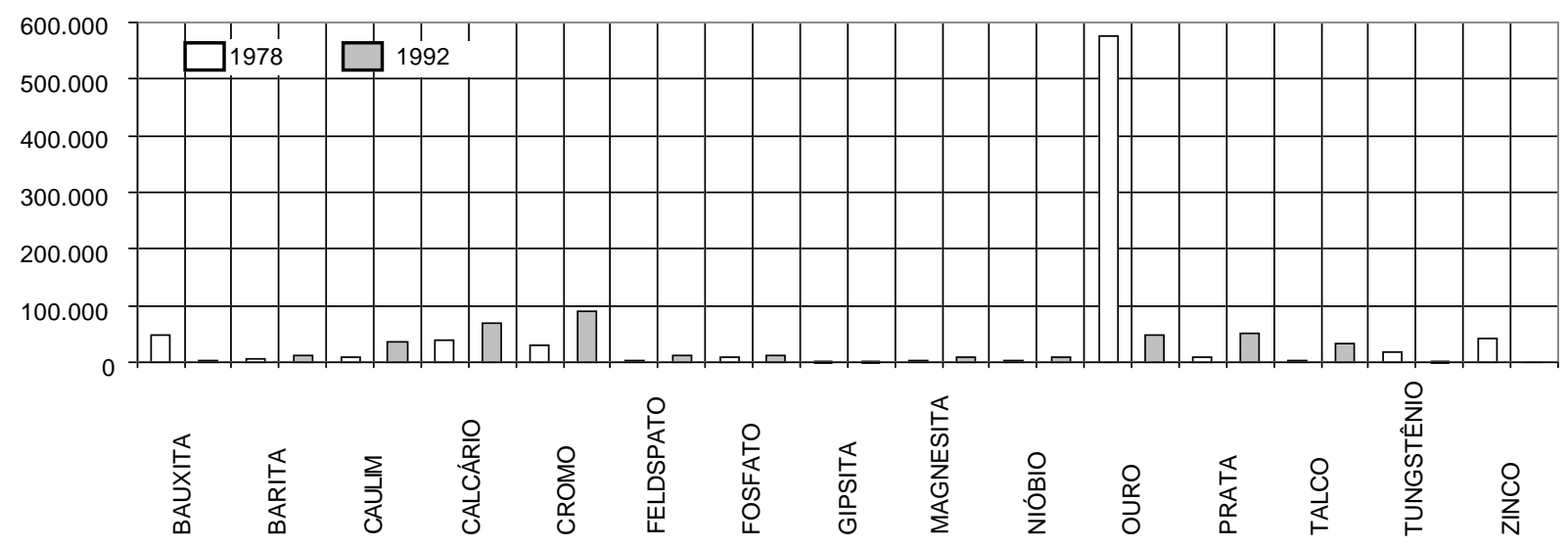

Figura 4: Total investido em pesquisa mineral: 1978 e 1992 (US\$ 1.000).

Figure 4: Total investment in mineral exploration in Brazil: comparison between 1978 and 1992 values (US\$ 1.000).
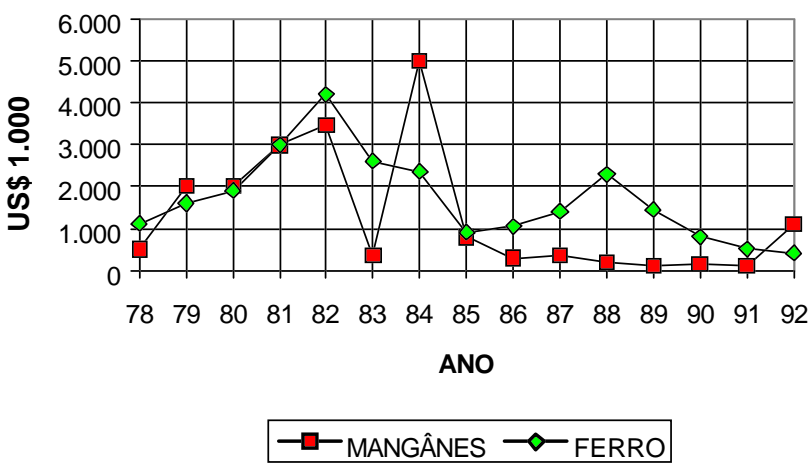

Figura 5: Investimento em pesquisa mineral: ferro e manganês no Brasil, 1978-1992.

Figure 5: Investment in mineral exploration of iron and manganese in Brazil, 1978-1992.

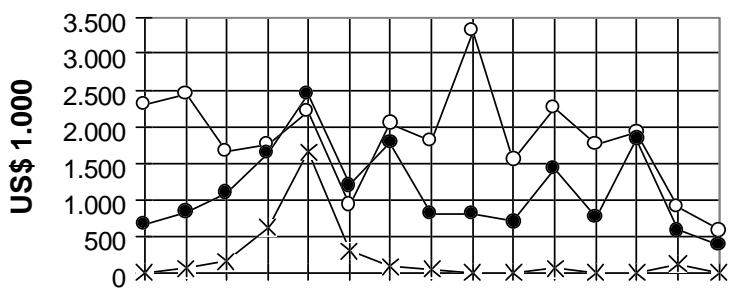

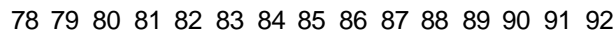

ANO

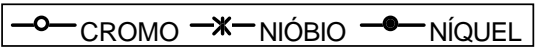

Figura 6: Investimento em pesquisa mineral: metais ferrosos no Brasil.

Figure 6: Investment in mineral exploration of ferroalloys in Brazil, 1978-1992. 


\section{COMO VAI A MINERAÇÃO}

No que se refere à exploração geológica, a Mineração cumpre exatamente o destino que lhe foi reservado pela sociedade brasileira, muito bem representada na Assembléia Constituinte. Pouco recurso é dirigido à atividade exploratória e nenhuma descoberta notável se registra, como consequência do pouco esforço exploratório que se fez nos últimos 15 anos.

Para complicar a vida do minerador, a mineração passou a ser o alvo preferido dos órgãos ambientalistas, e até que se consolide uma sistemática processual e racional de exames e aprovações, a mineração estará à mercê dos caprichos dos ambientalistas e, porque não dizer, também dos chantagistas que proliferaram "no meio ambiente". À sociedade brasileira, a imprensa apresenta o retrato da mineração pelas agressões ambientais praticadas pelas "mineradoras", colocando a mineração na vala comum da marginalidade mineral, onde os órgãos ambientalistas não ousam aplicar suas punições. Afinal, a "Constituição Cidadã" prevê que esta marginalha seja enquadrada na legislação ambiental.

Alguma cousa de positivo vem acontecendo com a mineração: a privatização de empreendimentos estatais colocou nos devidos eixos algumas minas implantadas temerariamente; o setor do carvão perdeu seu mercado cativo junto à siderurgia e agora é tratado simplesmente pelo seu valor energético, como sempre deveria ter sido; as empresas do setor de minério de ferro, livres do CIP (que Deus o tenha no lugar merecido), tratam o mercado nacional como parte do mercado mundial; o minério de ferro disputa o mercado internacional acirradamente e esta disputa reflete no comportamento empresarial, especialmente nas posturas da CVRD e MBR. Quem vive o quotidiano da mineração brasileira não pode negar uma evolução positiva nos comportamentos empresariais e profissionais.

\section{O QUE SE PODE ESPERAR}

A partida da mineração brasileira em direção ao futuro ainda não foi preparada e a preparação demandará muito tempo. Muitos países já programaram a mineração do seu futuro, pois compreenderam seus erros passados e deles já estão livres.

O Brasil terá muito o que fazer e esta tarefa não será fácil, mesmo se o passado vier a ser razoavelmente compreendido pelos brasileiros. Um novo arcabouço legal terá que ser construído, qualquer que sejam os preceitos constitucionais que venham reger a mineração.

Os órgãos federais, especialmente o DNPM, terão que ser reestruturados, prestigiados e agilizados de modo a impedir que o novo arcabouço legal seja timidamente cumprido, dando lugar a interpretações casuísticas e cartoriais.
A sistemática dos órgãos ambientalistas deverá ser consolidada, afastando-se, antes de mais nada, a presença das tais "organizações representativas da sociedade civil", que, na verdade, nada representam, a não ser o interesse de um pequeno grupo ideologicamente ativo.

Enfim, o que se necessita são regras que, mesmo sendo duras, sejam claras e racionais.

Conseguido este milagre, teremos um longo caminho de reconstrução, pois os recursos disponíveis para tão arriscados empreendimentos demorarão a acreditar que o bom senso tenha sido definitivamente restabelecido "nos tristes trópicos".

Enquanto isto, o País terá de contar com a coragem de um seleto grupo de mineradores que, com a capacitação de sua equipe, saiba aproveitar o que de bom se construiu no passado, arriscar bastante no futuro, prestigiar os verdadeiros órgãos de apoio à mineração, os centros de pesquisa, os prestadores de serviços e os fornecedores. Felizmente, pode-se notar que num selecionado grupo de Empresas de Mineração estes princípios singelos vêm sendo observados num claro programa de valorização profissional.

\section{NESSE CONTEXTO, MINAS GERAIS}

Quando se falou em mineração, a primeira referência define-se no estado de Minas Gerais, onde tudo se passou, na vivência do drama que se descreveu. Fora de Minas Gerais, mas no mesmo contexto histórico, em escala mais modesta, tramas paralelas foram vividas em outras regiões. De vida independente e notável, registram-se as atividades de mineração de carvão, no sul do País, e de aproveitamento da schelita, no nordeste. Minas Gerais sempre englobou a grande parcela da atividade mineira do Brasil, até que, na década de 1960, surgem outros polos importantes, notadamente em Rondônia e no Pará, reduzindo a participação mineira de valor aproximado de $60 \%$ para valores próximos de $40 \%$. Entretanto, esta redução não é absoluta, mantendo Minas Gerais produção crescente, com perdas nos setores de manganês, diamante e cassiterita. Os acréscimos absolutos dão-se nos setores de ferro, ouro, zinco, bauxita. As perdas relativas dãose nestes mesmos setores, excluído o zinco.

Esta tendência parece que permanecerá, com grande crescimento da produção do Pará. Em pormenores ele pode ser, então, analisado:

Ferro - As jazidas da Serra dos Carajás, caracterizadas por qualidade excepcional dos minérios e, consequentemente, de tratamento simples e pouco oneroso, já contando com um sistema logístico de alta confiabilidade, deverão sustentar prioritariamente os programas de expansão da Companhia Vale do Rio Doce, detentora exclusiva dos direitos minerários. As atividades mineiras (de Minas Gerais) desta empresa, no setor de ferro, dará prioridade ao abastecimento interno e tende a ser claramente complementar nos seus programas de exportação. Entretanto, os demais 
mineradores, contando unicamente com fontes de Minas Gerais, compensarão, em parte, estas perdas relativas.

Ouro - A produção de ouro em Minas Gerais tenderá a crescer, como resultado dos intensos programas exploratórios implantados em épocas mais favoráveis. Sua posição relativa poderá sofrer deslocamento ligeiramente negativo, em consequência dos avanços dos empreendimentos em áreas de outros estados, especialmente na Bahia, Goiás, Mato Grosso e na Amazônia, em geral. A perda relativa não deverá ser tão violente como o foi na época áurea do "garimpo" amazônico.

Bauxita - Destinada unicamente para abastecimento, não exclusivo, das usinas situadas no sudeste, a produção de bauxita lavrada em Minas Gerais sofrerá grande perda relativa e não acompanhará o desenvolvimento reservado à produção de bauxita amazônica, onde se desenvolve o grande polo exportador de alumínio. A dimensão da perda relativa de produção de bauxita de Minas Gerais, ou seja, o aumento da produção, dependerá da recuperação e modernização de sua logística, cujo componente principal é o que resta da antiga Estrada de Ferro Leopoldina, hoje operada pela RFFSA.

Caulim - A produção de caulim em Minas Gerais crescerá, mas seu volume será insignificante comparativamente ao que se produzirá no Pará, ocorrendo, então, brutal perda relativa.

Manganês - A decadência da mineração de manganês de Minas Gerais será irreversível. Ela atenderá parcialmente às necessidades locais sob pressão das novas fontes (Pará e Mato Grosso).

Diamante - Há uma queda violenta na produção de diamantes, neste momento de valor insignificante com a paralização da Mineração Tijucana. O modesto futuro do diamante dependerá do grau de retomada que se possa dar à extração no Vale do Jequitinhonha.

Zinco - A produção de minério de zinco, basicamente de willemita, não poderá expandir-se, pois as reservas conhecidas não o permitirão. Nada indica que o panorama de fontes sulfetadas de zinco venha a se modificar, mantendo-se na modéstia das reservas de Morro Agudo. De qualquer forma, nenhuma outra alternativa parece surgir às modestas reservas de Minas Gerais.

Titânio - Embora possuidor de gigantescas reservas de titânio, os esforços para aproveitamento das reservas de anatásio ainda não conduziram a um final de sucesso, este definido como um empreendimento industrial competitivo. As reservas aluvionares de ilmenitas recentemente exploradas não resultaram em dimensões que justificassem a explotação. Essas ilmenitas aluvionares apresentam características de reatividade muito interessantes e se se localizassem próximas a unidades industriais preexistentes seriam bem recebidas pelos consumidores.

Níquel - Minas Gerais espera com ansiedade a força empreendedora que poderá viabilizar o aproveitamento das reservas de Fortaleza de Minas. Capacidade e audácia já foram mostradas pelo interessado, em outra oportunidade.

Minas Gerais poderá se tornar o primeira unidade da federação onde a problemática de conciliação da conservação do meio ambiente com a atividade de mineração venha a consolidar-se em regras institucionais, nítidas e criteriosas, embora necessariamente rigorosas. Não se pode esperar que o meio ambientalista venha a ser, tão cedo, forte e predominantemente racional, mesmo porque a falta de outras novidades ideológicas continuará sendo suprida por assuntos palpitantes que possam, pelo mau uso, satisfazer rancores e frustrações. Mais que qualquer alteração constitucional na definição da "empresa brasileira", a consolidação racional das regras que regerão a proteção ambiental é condição essencial para desenvolvimento da verdadeira indústria mineral e para asfixia de atividades semi-clandestinas e marginais depredadoras de jazidas e ameaçadora do equilíbrio no meio ambiente.

O futuro imediato da mineração em Minas Gerais muito depende do destino que será dado à rede ferroviária operada pela RFFSA. Aliás, todo futuro econômico de Minas Gerais é uma função em que a rede ferroviária é importante variável. Fazer pela infraestrutura é o maior programa de fomento que se pode reservar à mineração mineira.

\section{REFERÊNCIAS BIBLIOGRÁFICAS}

ABREU, Sylvio Froes. Recursos Minerais do Brasil - USP - 1973. BRASIL MINERAL, Ano XI - nº 118 e 119 - Signus Ed. Ltda.

BURTON, Richard. Viagem do Rio de Janeiro a Morro Velho 1869 - SP/BH: USP/Itatiaia - 1976.

CAMPOS, Roberto de Oliveira. A Lanterna na Popa - 1994 Topbooks Editora e Distribuidora de Livros Ltda. -RJ.

CÓDIGO DE MINERAÇÃO E LEGISLAÇÃO CORRELATIVA 1982 - DNPM.

COMPANHIA DE MINERAÇÃO NOVALIMENSE, A Tentativa de Confisco das Minas de Ferro da, (o "Caso Hanna”) - 1963 Mandato de Segurança $n^{\circ}$ 29.881/DF.

COMPANHIA VALE DO RIO DOCE, 40 anos - 1982.

COMPANHIA VALE DO RIO DOCE, 50 anos de História - 1992.

ESCHWEGE, Wilhelm Ludwig von. Pluto Brasiliensis - 1833 - SP/ BH: USP/Itatiaia - 1978.

PLANO PRURIANUAL PARA O DESENVOLVIMENTO DO SETOR MINERAL - DNPM - 1994

POHL, Johann Emanuel. Viagem no Interior do Brasil - 1832 - SP/ BH: USP/Itatiaia - 1976.

RESENDE, Ronaldo Márcio. Cadastro Geral das Minas Brasileiras - 1982 - DNPM.

SAINT-HILAIRE, Auguste de. Viagem pelas Províncias do Rio de Janeiro e Minas Gerais - 1830 - SP/BH: USP/Itatiaia - 1975.

SAINT-HILAIRE, Auguste de. Viagem pelo Distrito dos Diamantes e Litoral do Brasil - 1830 - SP/BH: USP/Itatiaia - 1975.

SAINT-HILAIRE, Auguste de. Viagem às Nascentes do Rio São Francisco - 1847 - SP/BH: USP/Itatiaia - 1975.

SAINT-HILAIRE, Auguste de. Viagem à Província de Goiás - 1830 - SP/BH: USP/Itatiaia - 1975 